\title{
Correction to: Review of Landsat False Color Composite Images for Lithological Mapping of Pre-Cambrian to Recent Rocks: A Case Study of Pail/Padhrar Area in Punjab Province, Pakistan
}

\author{
Rizwan Saqib Bajwa ${ }^{1}$ (D) Naveed Ahsan ${ }^{1} \cdot$ Sajid Rashid Ahmad ${ }^{2}$
}

Published online: 21 April 2020

(C) Indian Society of Remote Sensing 2020

Correction to: Journal of the Indian Society of Remote Sensing

https://doi.org/10.1007/s12524-019-01090-7)

Unfortunately, Fig. 1 was published incorrectly in the original article. Hereby, the correct figure is given below.

The original article has been updated accordingly (Fig. 1).

Rizwan Saqib Bajwa

saqibrizwan83@gmail.com

Naveed Ahsan

naveedahsan@ymail.com

Sajid Rashid Ahmad

sajidpu@yahoo.cm

1 Institute of Geology, University of the Punjab, Lahore 54590,

Pakistan

2 College of Earth and Environmental Sciences, University of the Punjab, Lahore 54590, Pakistan 


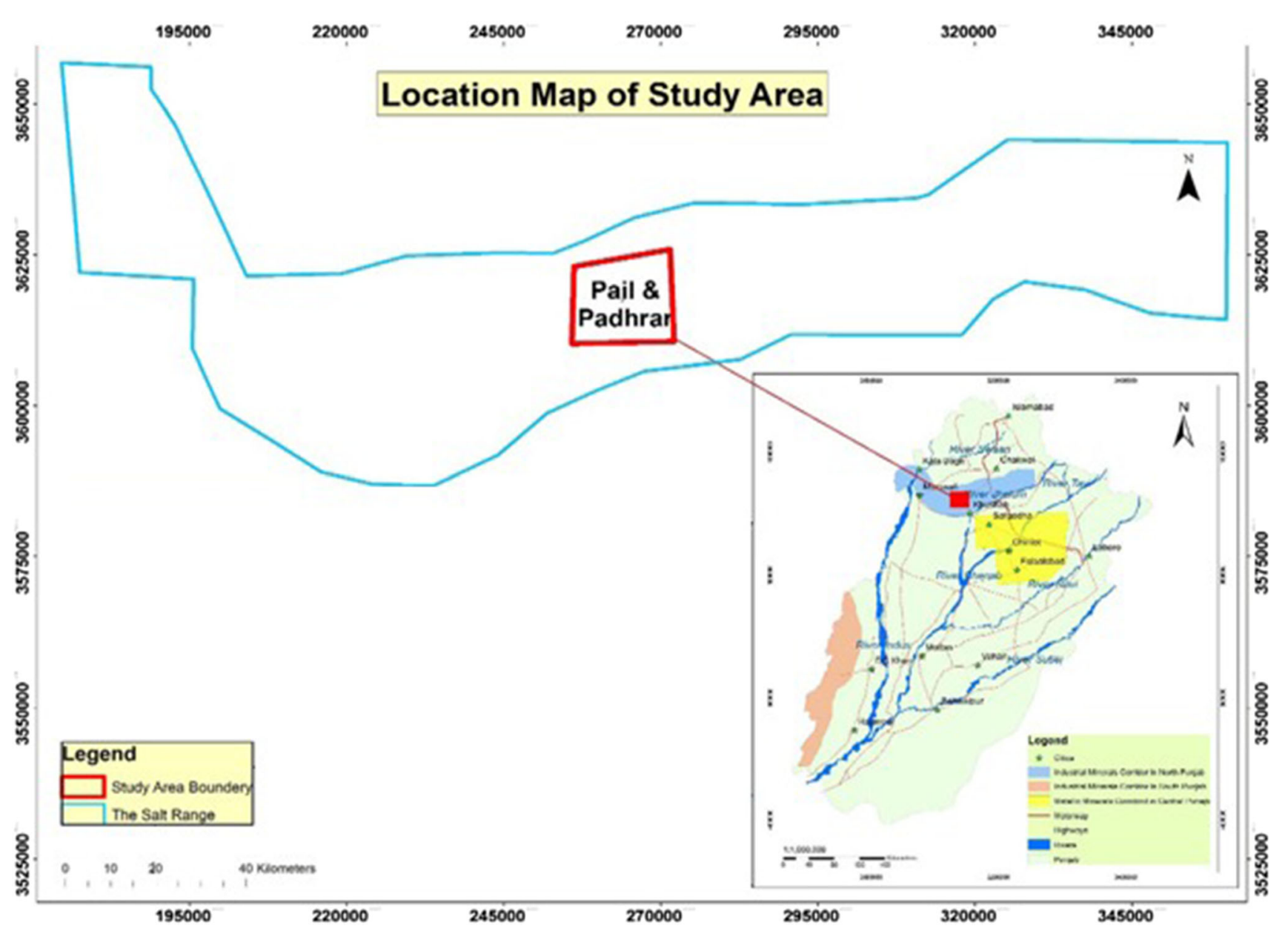

Fig. 1 Location map of the study area

Publisher's Note Springer Nature remains neutral with regard to jurisdictional claims in published maps and institutional affiliations. 